\title{
Materialismo e história: o caso do Barão d'Holbach
}

M aria das Graças de Souza

mgsouza@usp.br

Universidade de São Paulo, São Paulo, Brasil

resumo Trata-se, em primeiro lugar, de examinar em que medida o monismo materialista, tal como se apresenta na obra Sistema da natureza de Holbach, de 1770, permite a formulação de uma concepção original da história, para, em seguida, averiguar se esta concepção do curso geral dos acontecimentos humanos poderia ser identificada na História natural da superstição, do mesmo autor.

palavras-chave materialismo; história; Iluminismo; liberdade; superstição; Holbach

A questão que se apresenta de início é a seguinte: se o princípio que dirige o materialismo das Luzes pode ser definido como uma redução do mundo propriamente humano ao campo da matéria, ou seja, ao campo da determinação natural, como pensar a história, se a entendermos como o domínio próprio da vontade e da ação humana, lugar próprio da indeterminação, da criação, enfim, da liberdade?

C omo bem mostraY ves Zarka, o materialismo não poderia se limitar a uma afirmação monista da matéria. É preciso, além disto, que ele explique o modo pelo qual a matéria engendra o mundo diferenciado que conhecemos até as operações do pensamento, passando pela fisiologia, a moral e a política. Se a matéria é a definição do existente, deve ser possível fornecer uma teoria unificada dos acontecimentos, quer dizer, produzir um sistema da natureza (ZAR KA, 2006, p. X III). A lém disto, eu perguntaria se seria possível, a partir da metafísica materialista, formular uma interpretação do mundo histórico.

R ecebido em 22 de maio de 2011. A ceito em 8 de junho de 2011.

doispontos, Curitiba, São Carlos, vol. 8, n. 1, p.23-36, abril, 2011 


\section{4}

\section{1- 0 Sistema da Natureza}

O título geral, Sistema da natureza, se divide em dois subtítulos, que são os das duas partes: $\mathrm{D}$ a naturez a e 0 rigem de nossas ideias sobre a divindade. Se consideramos os 17 capítulos da primeira parte, cinco deles dizem respeito à matéria e remetem ao sistema da natureza como organização objetiva de elementos materiais e os doze seguintes concernem ao homem. Os cinco primeiros desenvolvem a ideia de natureza, que engloba e unifica os aspectos múltiplos da matéria, pensada como conjunto de combinações diferentes e movimentos diferentes. A redução desta pluralidade ao singular "natureza" se dá pelo pressuposto de uma racionalidade comum a todos os elementos. Ela é ao mesmo tempo uma realidade, a soma de tudo o que existe, e um valor, pois é a partir dela que serão julgadas as outras pretensas realidades (espírito, deus, alma, etc). É isto que vai permitir a introdução do tema do homem a partir do capítulo 6.

0 homem é tratado com a mesma estratégia com que a natureza em geral foi tratada nos cinco primeiros capítulos. "A pliquemos, agora, diz o barão, aos seres da natureza que mais nos interessam [0s homens], as leis gerais que acabam de ser examinadas" (H O LBACH , 2008, p. 51). A ssim como havia passado da natureza, no singular, à diversidade do elementos e dos movimentos, $\mathrm{H}$ olbach passa do homem, no singular, à multiplicidade das faculdades. A sociedade aparecerá no capítulo 9 como uma das características do ser humano. M as o homem é pensado primeiro como indivíduo singular e os fenômenos por assim dizer sociais são tratados num segundo plano. Com o homem, aparece o dualismo do físico e do moral. D este modo, os capítulos seguintes examinarão alternadamente, 0 espiritualismo (cap. 7) e o sensualismo (8 e 9); a liberdade (11) e o fatalismo (12); as ideias falsas (16) e as ideias verdadeiras (17).

0 programa do capítulo 6 é assim anunciado: examinar o que 0 homem tem em comum com os outros seres; não obstante as diferenças sob alguns aspectos, há uma conformidade; o homem age por regras universais às quais tudo está submetido. Em seguida, trata-se de verificar se as ideias que o homem produziu sobre si mesmo se sustentam ou não, quer dizer, se são quiméricas ou têm fundamento. Portanto, uma primeira parte propositiva, uma segunda parte crítica. 
A essência do homem, dentre todos os seres da natureza, consiste num modo de ser que o torna suscetível de diversos modos de agir ou de movimentos, dentre os quais alguns são simples e outros inteiramente complexos e ocultos aos nossos olhos. Todos os seus modos de agir têm causas, sejam causas externas - 0 ar, tudo que o rodeia, os alimentos dos quais se nutre, as coisas que lhe afetam os sentidos - sejam internas como seu sangue, seus nervos, sua carne, tudo o que compõe o seu corpo. Em suma, o homem é corpo, afetado por outros corpos. Todas estas causas, internas ou externas, operam nele mudanças contínuas.

0 homem tem em comum com todos os seres naturais a tendência a se conservar e a resistir à sua destruição. É atraído por objetos que lhe são análogos, repele aqueles que Ihe são contrários. Procura uns, afasta-se de outros. Suas ações, seus estados, suas tranforormações são regulados pelas mesmas leis que regulam os outros seres da natureza. Ele é, em sua origem, um ponto imperceptível, informe. N o embrião, não percebemos nenhuma qualidade tal como as que chamamos de sensibilidade ou inteligência. C resce na sua matriz própria, o útero, cresce por adição de matérias análogas, que se combinam, se assimilam mutuamente. $\mathrm{N}$ ascendo, se fortalece, cresce, se torna adulto. N este processo, seu corpo tornouse sensível; tornou-se uma massa viva que age, pensa, capaz de escolha, capaz de trabal har mais ou menos eficazmente para a sua própria conservação. Suas manei ras de agir, suas sensações e seus pensamentos são efeitos necessários de suas propriedades. M as quais são estas propriedades?

Segundo Holbach, os seres da espécie humana, assim como todos os seres naturais, são suscetíveis de duas espécies de movimentos. U m é 0 movimento pelo qual toda a massa do corpo ou algumas de suas partes são transferidas visivelmente de um lugar para outro. 0 outro é movimento interno, dos quais alguns nos são sensíveis, e outros ocorrem à nossa revelia, e só seus efeitos são percebidos. 0 homem vê bem que seu corpo age; mas, não podendo perceber a causa desta ação, acreditou que possuía, encerrado em si, um princípio motor diferente do corpo, que lhe dava impulsão. Este princípio, que o homem acreditou ser a causa do que Ihe ocorre no corpo, foi entendido como movido por si mesmo, e segundo leis que agem de modo inteiramente distinto do próprio corpo, uma outra substância dotada de uma força secreta. D aí vieram todas as noções de imaterialidade e espiritualidade da alma, para assinalar os atributos 
desta substância desconhecida. M as, tudo bem examinado, diz 0 autor: "0 homem é um todo organizado composto de diversas matérias; do mesmo modo que todas as outras produções da natureza, ele segue as leis gerais e conhecidas, assim como leis ou modos de agir que lhe são particulares e desconhecidos" (HOLBACH , 2008, p. 56). Ele "não tem motivos para acreditar que é um ser privilegiado na natureza: está sujeito às mesmas vicissitudes que todas as outras produções naturais, e suas pretensas prerrogativas são fundadas no erro" (HO LBAC H , 2008, p. 61).

Dentre as prerrogativas que a tradição atribui equivocadamente ao homem está, evidentemente, a liberdade. A ssim, coloca-se para H olbach, assim como para qualquer doutrina monista materialista, a questão do livre arbítrio.

A o iniciar o capítulo 11 da parte 1, sobre a questão da liberdade, Holbach assinala a ligação entre a ideia de liberdade como livre arbítrio, ou como liberdade da vontade, e a doutrina da espiritualidade da alma. Ao afirmar que a alma é imaterial, os filósofos dualistas a livraram de quaisquer leis naturais, segundo as quais agem todos os seres, e, assim, acreditaram que a alma era completamente mestre de si e podia regular suas próprias operações, determinar sua vontade por sua própria energia.

O ra, o homem é um ser físico, e, como tal, ele está sujeito a todas as leis que a natureza impõe a todos os seres. $N$ ascemos à nossa revelia, nossa organização não dependeu de nós, nossas ideias dependem dos objetos exteriores, somos sem cessar modificados por causas visíveis ou invisíveis, que regram necessariamente nosso modo de ser, de pensar e de agir. Como pretender que determinamos nossas ações e nosso destino independente destas causas?

Para que o homem fosse livre, seria necessário que ele fosse, sozinho, mais forte que a natureza inteira; ou então que estivesse fora dela; seria necessário que ele não tivesse sensibilidade física, que não sofresse dores nem usufruísse de prazeres. $M$ as se isto acontecesse, ele não teria mais condições de se conservar, de conservar seu corpo.

A essência atual do homem é a de se conservar. O s movimentos de seu corpo vão sempre nesta direção; a dor o adverte que ele deve evitar o objeto que lhe causa este mal; o prazer o leva a procurar o objeto que Ihe dá esse bem. Por necessidade, sua vontade é arrastada na direção dos 
objetos que causam prazer e afastada dos que causam dor. A experiência é que nos ensina a amar ou temer.

O ra, a doutrina do livre arbítrio supõe que a vontade é uma faculdade independente do corpo e das outras faculdades intelectuais, e que ela é dotada de uma força ou autodeterminação, de tal forma que ela pode querer, não querer, afirmar, negar, aceitar, recusar, sem que nenhuma causa estranha a determine.

Situemos a polêmica sobre o livre arbítrio na filosofia moderna. Para D escartes, a vontade é uma potência positiva de se determinar, mesmo na ausência de uma ideia verdadeira. Ela é uma faculdade da alma, cuja essência é pensamento, e a demonstração de sua natureza ou ação é feita sem nenhum recurso ao corpo. Esta doutrina da vontade como livre arbítrio ou como potência de autodeterminação terá seus efeitos no Tratado das paix ões: aqui, os corpos já foram repostos, e agem sobre a alma, produzindo as paixões. $M$ as a vontade permanece um poder. "A vontade é, por natureza, diz D escartes, de tal modo livre, que nunca pode ser compelida. (...) E toda a ação da alma consiste em que, simplesmente por querer alguma coisa, leva a pequena glândula, à qual está estreitamente unida, a mover-se de maneira necessária, a fim de produzir o efeito que se relaciona com a vontade" (DESCARTES, 1996, p. 360). A alma tem força contra as paixões que vêm do corpo, pode combatê-las com armas próprias, que são juízos firmes e determinados sobre o conhecimento do bem e do mal. "Enfim, diz D escartes, não há alma que seja tão fraca que não possa, sendo bem conduzida, adquirir poder absoluto sobre suas paixões" (DESCARTES, 1996, p. 368).

$M$ as é do interior mesmo do cartesianismo que a doutrina da liberdade da vontade e de seu poder absoluto será contestada. N o L eviatã, H obbes define liberdade do ponto de vista estritamente físico: "por liberdade entende-se, conforme a significação própria da palavra, a ausência de oposição (entendendo-se por oposição os impedimentos externos do movimento)" (H O BBES, 2003, p 179). N o mesmo capítulo, lemos que 0 homem livre é aquele que, nas coisas que é capaz de fazer graças à sua força ou engenho, não é impedido de fazer o que tem vontade de fazer (H O BBES, 2003, p 179). E no capítulo 46, no livro II, H obbes situa entre as trevas resultantes da vã filosofia a noção de vontade como faculdade ou capacidade que os homens têm para querer às vezes uma coisa, às vezes 
outra, a qual é chamada voluntas (H O BBES, 2003, p. 564). O ra, ele já havia, no capítuloVI no início do L eviatã, afirmado que "na deliberação, o último apetite ou aversão imediatamente anterior à ação ou à omissão desta é o que se chama vontade, o ato, não a faculdade, de querer. (...) Portanto, vontade é o último apetite na deliberação" (H O BBES, 2003, p. 55).

Tomemos agora o prefácio do livro III da É tica de Espinosa.Trata-se, neste livro, da natureza dos afetos, ou das paixões. Começa Espinosa dizendo que os que escreveram sobre os afetos e o modo de vida dos homens parecem, em sua maioria, ter tratado não de coisas naturais, que seguem as leis comuns da natureza, mas de coisas que estão fora dela. $\mathrm{O}$ u melhor, parecem conceber o homem na natureza como um império num império. Q uer dizer, no império da natureza, há outro império, que é o homem.

Estes autores dizem que o homem, em vez de seguir a natureza, ele a perturba, que ele tem uma potência absoluta sobre suas ações e não é determinado por nada a não ser por si mesmo. Embora, continua Espinosa, não tenham faltado homens eminentes que tenham escrito sobre o modo de vida e tenham dado conselhos importantes, ninguém até hoje determinou a força e a natureza dos afetos. 0 próprio D escartes, que tentou aplicadamente explicar os afetos humanos por suas causas primeiras, acreditou que a mente tem um poder absoluto sobre os afetos e tentou mostrar a via pela qual se poderia adquirir domínio sobre eles. M as ele nada mostrou, a não ser a perspicácia de sua própria inteligência.

Ainda no prefácio do livro III, Espinosa afirma que a natureza é sempre a mesma, e que uma só e mesma, e em toda parte, é a sua potência de agir. Isto é, as leis e as regras da natureza, de acordo com as quais todas as coisas se produzem e mudam de forma, são sempre as mesmas em toda a parte. Os afetos possuem causas precisas, que é possível compreender. Espinosa dirá, ao final do livro IV, que, em relação aos afetos, a potência humana é muito limitada (IV, parágrafo final), e é infinitamente superada pelas causas exteriores. Somos uma parte da natureza inteira, cuja ordem seguimos.

N o prefácio do livro V, Espinosa volta a D escartes: com efeito, diz E spinosa, " D escartes afirma que a alma, ou a mente, está unida principalmente a uma certa parte do cérebro, mais especificamente, à chamada glândula pineal, por meio da qual a mente sente todos os movimentos do 
corpo bem como dos objetos exteriores" (ESPIN O SA, 2009,V, p.213) A mente, por sua vez, pode movê-la de várias maneiras, bastando querê-lo. D aí, continua Espinosa, D escartes conclui “que nenhuma al ma é tão débil que não possa, se bem dirigida, adquirir um poder absoluto sobre as paixões. (...) esta é a opinião deste ilustríssimo homem. Tratando-se de um filósofo que havia se proposto firmemente nada deduzir que não fosse de princípios evidentes por si mesmos e nada afirmar senão aquilo que percebesse clara e distintamente, (...) não posso surpreender-me 0 bastante de que um tal filósofo admita uma hipótese mais oculta do que todas as qualidades ocultas" (ESPIN O SA, 2009,V, p.214)

No escólio da proposição 2 do livro III, Espinosa demonstra que a mente e o corpo são uma e a mesma coisa, a qual é concebida ora sob o atributo do pensamento, ora sob o atributo da extensão. D isto resulta que "a ordem e o encadeamento das coisas é uma só (...) e a ordem das ações e das paixões de nosso corpo é simultânea, em natureza, à ordem das paixões e ações da nossa mente. D isto se segue que quando os homens dizem que esta ou aquela ação provém da mente, que ela tem domínio sobre o corpo, não sabem o que dizem, e não fazem senão mais do que confessar com palavras enganosas, que ignoram a verdadeira causa desta ação. O s homens se julgam livres apenas porque estão conscientes de suas ações, mas desconhecem as causas pelas quais são determinados" (ESPIN O SA, 2009 III , 2, p. 100).

A presentado este horizonte, voltemos a H olbach. Q uando ele escreve seu capítulo sobre a liberdade, muitas águas já haviam corrido, e as suas reflexões apresentam muitos pontos em comum com H obbes e Espinosa.

A vontade, diz $\mathrm{H}$ olbach, é uma modificação do cérebro pela qual ele está disposto ou preparado de forma a colocar em ação órgãos que ele pode mover. Esta modificação é determinada pela qualidade boa ou má, agradável ou desagradável do objeto que age sobre nossos sentidos ou cuja ideia nos é fornecida pela memória. $E$, consequência desta modificação, nós agimos. N ossa ação é um efeito do impulso que recebemos de um objeto ou de uma ideia que modificaram nosso cérebro ou dispuseram nossa vontade. É assim que a vista de um objeto agradável nos dispõe a procurá-lo e vice-versa. N ossa ação também pode ser interrompida quando um objeto novo nos faz voltar atrás e não realizar a ação antes iniciada. 
Q uando deliberamos, a vontade cessa. Q uando um objeto nos causa ao mesmo tempo amor e ódio, nossa vontade fica em suspenso, pelo menos até que um dos objetos se imponha a nós com mais força. $M$ as esta escolha não significa liberdade do homem. Sua escolha é necessária, porque ele só delibera quando tem ideia do benefício de escolher em direção a um objeto mais do que a outro. Para que se pudesse dizer que o homem é livre, seria necessário afirmar que ele escolhe sem motivo ou sem causa, ou que ele pudesse impedir as causas de agirem sobre ele. Como a ação é sempre o efeito de uma vontade determinada, e como a vontade é determinada por motivos que não estão em nosso poder, segue-se que não somos nunca senhores das determinações de nossa vontade, e que portanto não agimos livremente.

Se sou atormentado pela sede, não sou mestre de querer ou não querer a água e agir para bebê-la. M as se dizem que a água está envenenada, paro de querê-la, apesar da sede. $\mathrm{N}$ os dois casos meu querer é determinado.

Todas as causas que agem sobre a vontade devem ter agido sobre nós de uma maneira bastante notável para produzir em nós alguma sensação, percepção, ideia, completa ou incompleta, verdadeira ou falsa. D esde que minha vontade se determina, devo ter sido afetado, fortemente ou não, sem 0 que eu me teria determinado sem motivo. Para a vontade, não há causas indiferentes. Em consequência de uma afecção fraca, serei fracamente determinado, e ao contrário também.

O s defensores do livre arbítrio dirão que, se não há liberdade, não haverá vício nem virtude, e, consequentemente, não poderá haver recompensa nem punição; dirão também que o sistema do fatalismo é desencorajador para os homens, e, enfim, que retirar do homem a liberdade significa aviltá-lo.

À primeira objeção, Holbach responde que imputar uma ação a al guém é atribuir esta ação a esta pessoa, é reconhecê-la como sua autora. Assim, mesmo que se considere que esta ação é um efeito de certas causas necessárias, a imputação pode ser feita. Em outras palavras: 0 mérito ou demérito que atribuímos a uma ação são ideias fundadas sobre os efeitos favoráveis ou perniciosos desta ação que resultam para aqueles que os experimentam. M esmo se se reconhece que 0 agente agiu por necessidade, nem por isto deixa de ser certo que esta ação é boa ou má, estimável ou desprezível para aqueles que sentirão a sua influên- 
cia. 0 fatalismo não confunde vício e virtude. Aliás, as leis penais são outros tantos motivos que entram nas causas que levam os homens a agir ou deixar de agir. Elas são capazes de conter ou contrabalançar impulsos. Q ualquer que seja a causa das ações dos homens, pode-se interromper seus efeitos (como se pode conter a violência das águas por meio de um dique).

À segunda objeção, responde que somos seres sensíveis, e dificilmente conseguiríamos permanecer indiferentes a alegrias ou tristezas. A lém disto, é certo que as especulações influem pouco na sensibilidade dos homens, e se elas, as especulações, pudessem influir muito, o sistema da necessidade seria muito mais benéfico do que o sistema da liberdade. Ele seria mais adequado para acalmar nossas inquietações. 0 sistema da necessidade, além disto, nos tornaria mais indulgentes e tolerantes. A partir do princípio segundo o qual tudo é necessário, o fatalista não insulta, não despreza os seus semelhantes,

Final mente, quanto à tercei ra objeção, que afirma que negar liberdade ao homem é aviltá lo, dirá o barão que esta é uma linguagem inventada pela ignorância da verdadeira dignidade do homem. $\mathrm{N}$ ão há nada de vil na natureza, e nenhum ser natural é vil.

A adoção do determinismo ou do fatalismo, portanto, não interfere no sistema moral, na medida em que, se o compreendermos corretamente, ele não conduz, como pretendem os espiritualistas e teólogos, a confundir o vício e a virtude, o justo e o injusto, o bem e o mal. É claro que isto quer dizer, em primeiro lugar, que o materialismo não justifica o vício nem a imoralidade. M as isto quer dizer também outra coisa: que, ao evitar relacionar as condutas virtuosas ou viciosas a uma suposta vontade livre, se pode dar às práticas jurídicas e políticas (punições, recompensas, etc) uma interpretação mais exata, pois que livre de toda suposição sobrenatural. $M$ ais do que isto, a doutrina da necessidade universal cura os homens das paixões tristes como o ódio e o desprezo dos homens, assim como da admiração ingênua. 0 tema pessimista da maldade humana é substituído pelo tema dos efeitos necessários. A moral da condenação e da culpabilidade é substituída pela indulgência, pela tolerância e pela compaixão.

Pode-se então compreender por que o sistema da fatalidade possa ser apresentado pelo autor como um sistema que inspira segurança, como uma verdade consoladora. $\mathrm{N}$ ão se trata apenas de criticar o sistema do 
livre arbítrio e a ideia de que o homem possa ser um império num império, como diz Espinosa, e afirmar o fatalismo sem tristeza.Trata-se de afirmar que o destino humano repousa sobre uma base material; que tudo nos homens é efeito de causas insensíveis no seu corpo, seus humores, mas também de causas exteriores, feitas de encontros imprevisíveis que chamamos impropriamente de acaso, e que na realidade designam um encadeamento de causas imperceptíveis. $M$ as, ao invés de fazer desta precariedade um argumento para submeter os homens a uma transcendência e negligenciar sua natureza finita, $\mathrm{H}$ olbach faz disto 0 motivo de um apelo à tranquilidade (HO LBACH , 2008, p.. 158).

A segunda parte do Sistema da natureza analisa o que pode ser chamado de quimeras criadas pelo espírito humano. Se a primeira era reservada à verdade, a segunda é reservada ao erro. 0 s capítulos 1 a 7 desenvolvem uma explicação dos sistemas religiosos e uma história da ideia de deus. O s capítulos seguintes mostram a inutilidade de todos os dogmas religiosos (8 a 10), e os benefícios do ateísmo (11 a 13). 0 capítulo final se chama "R esumo do código da natureza". Se um código é uma coleção de leis, a natureza então é aqui elevada à condição de legisladora. A natureza então é, em primeiro lugar, objeto de uma constatação ou descrição, e em seguida ela passa a ser uma natureza que estabelece o que deve ser.

Com efeito, já no prefácio da obra, H olbach apresenta o erro como uma espécie de pecado do orgulho: o homem quis lançar-se para além do mundo visível, quis, como ícaro, voar com asas de cera. $\mathrm{N}$ ota-se, ao mesmo tempo, neste prefácio, a apresentação de uma espécie de drama intemporal do homem e a consideração da dimensão histórica que situa a falta no passado. 0 futuro aparece como lugar da conquista da verdade e da felicidade. A perdição do gênero humano no erro pode ser corrigida quando as causas desta perdição forem nomeadas e quando os responsáveis por esta perdição forem postos a descoberto: os padres, os tiranos, que colocam vendas nos olhos dos homens de modo que não veem a verdade. $\mathrm{N}$ ão há, ao que parece, uma fatalidade, ou uma inclinação congênita dos homens para o erro, mas uma ação de impedir a visão da verdade por parte dos inimigos do gênero humano.

Os primeiros inimigos do gênero humano são assim nomeados: os padres e os tiranos. D iante destes inimigos, quem combate? 0 parágrafo 
segundo, que descreve o contra-ataque aos inimigos, se caracteriza por fórmulas impessoais: é tempo, é preciso. N o quarto parágrafo, da mesma natureza que o segundo, introduz um nós: afastemos, etc. A causa da natureza deve ser defendida pelos que combatem os preconceitos. A vitória da natureza aparece como resultado de uma luta. $M$ as por que certos homens são capazes de enganar os semelhantes, ou em outras palavras, qual a causa do aparecimento dos impostores, de um lado, e, do outro, dos lúcidos, que querem tirar os homens do erro? 0 homem, tomado individualmente ou coletivamente, é um animal crédulo e fácil de seduzir. É preciso inspirar-Ihe o respeito pela sua própria razão.

A explicação, contudo, não se limita a apontar a credulidade do homem. De um lado está a credulidade, do outro, os impostores. A impostura: há uma espécie de "corja", ou claque, ou bando de déspotas e padres que se apóiam mutuamente, a qual forjou um sistema de mentiras para dominar o povo crédulo. A referência aos inimigos do gênero humano, cujo poder só subsiste por causa da noite obscura que eles difundem nos espíritos - "as correntes esmagadoras que os tiranos e os padres forjam em todas as nações" - , não esconde o fato de que o texto permite uma hesitação entre a tese de uma dominação tramada pelos tiranos e padres e a tese segundo a qual há uma inclinação ao erro por assim dizer "natural" ao homem.

0 que se pode perguntar é se estes chamados impostores conhecem a verdade e deliberadamente a escondem, ou se eles mesmos são vítimas do fermento que contamina os conhecimentos. 0 ra, o início do parágrafo 3 Ihes veda o acesso à verdade: "a verdade não deve falar a estes homens perversos. Sua voz é ouvida por corações honestos..." (HO LBACH , 2008, p. 6) Como então buscar a origem da ilusão e do erro que propagam num projeto consciente e deliberado de enganar? O u seja: se as frações dominantes (no caso, os tiranos e os padres) asseguram sua dominação sobre o povo graças a uma ação sobre as imaginações, sempre prontas para aceitar relações imaginárias ao invés de relações reais, não foram elas mesmas levadas pela sua imaginação a estas falsas representações do real que difundem? De outro lado, se a imaginação explica os erros, os que os difundem agem também sobre a imaginação do povo. 0 texto mesmo não se pergunta se as quimeras não seriam necessárias aos homens. 
Enfim, a tese da impostura no prefácio do Sistema da natureza sugere implicitamente uma explicação psicológica da religião como projeção, ou da origem psicológica da ilusão e ao mesmo tempo uma explicação, por assim dizer, "ideológica" das falsas crenças, na medida em que elas seriam o resultado da ação deliberada de uma minoria cínica. A H istória natural da superstição retomará as linhas gerais desta explicação pela credulidade e pela impostura.

A H istória natural superstição se desenvolve a partir de duas teses principais: a religião como produto da imaginação dos homens e a origem sacerdotal do poder político. Segundo Holbach, os homens não têm medida comum quando se trata da imaginação. Eles variam pelo temperamento e pelas ideias, daí não ser possível decidir qual das suas fantasias é verdadeira. Portanto, não há religião verdadeira. Para que ela o fosse, seria necessário que tivesse por culto um deus verdadeiro. 0 ra, continua o barão, como encontrar o deus verdadeiro nesta multidão de divindades cultuadas pelas diversas nações? “ $O$ homem, diz H olbach, só é supersticioso porque teme; e só teme porque é ignorante. Por não conhecer a natureza, o homem supõe que ela está submetida a poderes invisíveis, dos quais acredita depender, e os imagina irritados ou favoráveis à sua espécie. Em consequência disto, ele imagina relações entre ele mesmo e estes poderes; ora se crê objeto de sua cólera, ora de sua ternura, e sua imaginação trabal ha para descobrir os meios de tornálos propícios ou de desviar o seu furor" (HO LBACH , 1768, tomo I, p.2).

Dir-se-á que o verdadeiro deus se revela ou se revelou aos homens. $M$ as entre todas as revelações feitas aos homens em todos os tempos, como escolher uma delas? Todas as revelações sufocam a razão, proíbem o livre exame, propõem mistérios. Lançam nosso espírito nas trevas. A lém disto, todas nos remetem à autoridade de homens a quem estas revelações teriam sido feitas. Se se disser que a revelação é prova da bondade de deus que quer se manifestar aos homens, pode-se responder que, se assim for, a revelação deveria ser universal. U ma revelação particular mostra a preferência por um povo particular, o que seria injusto para com os outros. Assim toda revelação exclusiva aniquila a bondade e a justiça de deus. A revelação, pois, é contrária à ideia mesma que se faz de D eus.

$\mathrm{N}$ a origem das sociedades, os legisladores foram os primeiros sacerdotes. Foram eles que trouxeram as divindades, as religiões, as mitologias, 
e se apresentaram como aqueles que podiam interpretar as vontades dos deuses. M as eles foram também os primeiros médicos, os primeiros juízes, e, consequentemente, os primeiros soberanos. "Todos aqueles, afirma 0 barão, que deram deuses, leis e cultos aos homens se anunciaram por descobertas úteis e maravilhosas aos olhos dos ignorantes; ganharam sua confiança antes de comandá los; fizeram-nos ter esperança no fim de seus males, julgaram que era importante nunca banir suas inquietações, e os mantiveram sempre suspensos entre a esperança e o medo" (H O LBACH, 1768, tomo I, p. 12)

A ssim, quanto mais conseguirmos retroceder aos tempos antigos, mais veremos o sacerdócio e o poder exercido pelos mesmos homens. Este poder era exercido de modo absoluto e despótico, já que as leis eram apresentadas como ordens de deus, e assim não podiam sofrer nenhum obstáculo. Certamente as leis penais eram assustadoras. A base deste governo foi o terror.

O governo sacerdotal era uma teocracia ou governo divino. Entretanto, com o passar do tempo, os abusos do governo sacerdotal levaram alguns a forçar uma partilha do poder soberano. Homens ambiciosos tiraram o cetro das mãos do déspota sacerdotal e se encarregaram da administração política, deixando os padres apenas com a tarefa de governar os espíritos.

Embora ainda guardassem o poder exclusivo de falar com os deuses, os padres, pouco contentes com o que Ihes tinha restado do poder, buscavam sempre recuperá-lo. N unca se submetiam completamente à autoridade política, e, sempre que Ihes interessava, a combatiam. A história mostra exemplos memoráveis da ascendência sacerdotal sobre os reis. O s próprios soberanos julgaram que não podiam governar sem 0 apoio dos padres. Assim, pode-se falar de uma cumplicidade entre 0 sacerdócio e a tirania.

Assim, o que temos em Holbach é uma visão da história segundo a qual o gênero humano, desde os inícios, sofre a influência nefasta da religião e dos poderes sacerdotais. Tudo se passa como se não houvesse movimento histórico real, ou, em outras palavras, a história do gênero humano aparece para Holbach como a cena contínua do peso do braço sacerdotal sobre os governantese os povos. 0 conteúdo do discurso sobre as origens recai também sobre 0 tempo presente; 0 diagnóstico 
permanecerá o mesmo enquanto os homens permanecerem na ignorância da verdadeira natureza das coisas. N este sentido, a concepção holbachiana da história se insere perfeitamente na perspectiva iluminista da história, para a qual a felicidade do gênero humano depende da descoberta progressiva da verdade, que o libertará dos poderes despóticos, cuja autoridade, desde as origens, se funda nas representações religiosas.

$\mathrm{N}$ otam-se, em H olbach, na verdade, duas posições complementares: em primeiro lugar, a afirmação de que a superstição tem origem nas paixões humanas. Trata-se de uma origem psicológica, de uma gênese da religião em nosso aparelho psíquico. Em segundo lugar, a explicação é de natureza, por assim dizer, sócio-política: os legisladores usaram habilmente a religião como instrumento de poder. A primeira posição nos remete a Freud: a religião como ilusão; a segunda nos remete a M arx: a religião como ópio do povo.

\section{Referências bibliográficas}

DESCARTES, R . 1996. Passions de I'âme. In: 0 euvres de D escartes, tome XI. Paris:Vrin.

ESPIN O SA. B. 2009. É tica. B elo H orizonte. Autêntica Editora

H O BBES, T. 2003. L eviatã. São Paulo: M artins Fontes.

HO LBACH . 1768. H istoire naturelle de la superstition. Londres.

H O LBAC H. 2008. L e système de la nature, ou L ois du monde physyque et du monde moral. Paris: Éditions C oda.

ZAR KA,Y. et alii, (orgs). 2006. M atérialistes français du dixhuitième siècle. Paris: PU F. 